\title{
Reproductive Biology of Mango (Mangifera indica) in a Mediterranean Climate
}

\author{
V. Pérez and J.I. Hormaza \\ Instituto de Hortofruticultura Subtropical \\ y Mediterránea La Mayora. IHSM, \\ UMA-CSIC. 29750, Algarrobo-Costa, \\ Málaga, Spain. \\ veronica@eelm.csic.es \\ ihormaza@eelm.csic.es
}

\author{
M. Herrero \\ Estación Experimental Aula Dei-CSIC. \\ Av. Montañana, 1005, 50059, Zaragoza, \\ Spain.
}

mherrero@eelm.csic.es

Keywords: Fruiting, embryo sac, pollen, pollen-pistil incompatibility, progamic phase.

\begin{abstract}
The importance of mango growing contrasts with the paucity of information on its reproductive biology. In this work, the reproductive biology of mango was studied in the subtropical conditions of the Southern Spanish Mediterranean coast, using the cultivars 'Osteen', 'Kensington', 'Kent' and 'Keitt'. In order to establish the appropriate developmental coordinates during the reproductive phase, phenology was studied from the start of the blooming season to fruit harvest. Also to detect the reasons behind the low fruit set in mango, pollen tube pathway and fertilization were analysed, using microscopy techniques. A good proportion of the flowers were male and dropped soon after anthesis. Pollen grains readily germinated, pollen tubes reached the base of the style within one day, penetrated the ovule through the nucellus and reached the embryo sac three days after pollination. Endosperm nuclei soon developed, but the embryo remained in a quiescent stage. A good proportion of the ovules degenerated at different stages of development. Temperature had an effect on pollen performance, and low temperatures hampered pollen germination. Finally, a compatibility assay was performed, showing no differences between self and cross pollen tube growth in the style. However a paternity analysis, with microsatellite markers, showed significant differences in outcrossing rate depending on the availability of pollinizer trees.
\end{abstract}

\section{INTRODUCTION}

In mango, even after adequate pollination, a very small proportion of the flowers are able to set fruits, due to a massive drop of flowers and developing fruitlets (Davenport and Nuñez-Elisea, 1997). This is especially important in areas such as Southern Spain, where climatic conditions are very different from those in the area of origin of the species, often resulting in erratic bearing.

The knowledge about the reproductive biology of species of agronomic interest (Herrero, 1992) and its relation with environmental conditions (Hedhly et al., 2009) is relevant in order to optimize production. But in mango, in spite of the importance of the crop, surprisingly very little is known on its reproductive biology. In this work, in order to study the ultimate causes behind this massive flower and fruitlet drop under a Mediterranean climate, we studied the process that goes from flower to fruit in mango, characterizing its phenology in the field and reproductive process under the microscope. 


\section{MATERIALS Y METHODS}

\section{Plant Material}

All the experiments were carried out in a mango germplasm collection maintained at the IHSM La Mayora ( $36^{\circ} 45^{\prime} \mathrm{N}$ ), except for one of the paternity experiments that was performed in a commercial orchard in Benamocarra $\left(36^{\circ} 47^{\prime} \mathrm{N}\right)$. Both orchards are located in Málaga, Spain. The cultivars used were 'Osteen', 'Kensington', 'Kent' and 'Keitt'. Phenology was characterized over three flowering season in adult trees. To characterize pistil growth, hand pollinations were performed in 'Osteen' using 'Kensington' pollen during 2010, 2011 and 2012 flowering seasons. Then, flowers were removed sequentially every day after pollination, from day 1 to 20 and weighted. To characterize flower/fruit drop, 10 inflorescences from 'Osteen' were bagged at the end of the flowering season, in 2010, and bags were opened and dropped flowers/fruits removed daily.

\section{Microscopy}

Ovules were removed from 'Osteen' flower buds fixed in FAA (70\% ethanol: glacial acetic acid: formalin [18:1:1; v/v/v]) (Johansen, 1940) at different development stages. Whole mount ovules were washed with distilled water and stained with acridine orange (Nicholas et al., 1986). Samples were examined with a fluorescence microscope using a 340-380 exciter filter and an LP 425 barrier filter. Pistils were similarly fixed at anthesis, embedded in resin (Lora et al., 2010), sectioned at $2 \mu \mathrm{m}$ and stained with acridine orange and examined with a fluorescence microscope. Sections were also stained with periodic acid-Shiff's reagent (PAS) followed by $0.2 \%$ toluidine blue in water (Feder and O'Brien, 1968) to observe insoluble carbohydrates and nuclei, and observed with a brightfield microscope.

To observe pollen tube growth, flowers were collected from the field and handpollinated in the lab, and then fixed in FAA at 4, 8, 12, 16 and 24 hours. Pistils were washed with distilled water, stained with $0.005 \%$ aniline blue in $0.15 \mathrm{M} \mathrm{PO}_{4} \mathrm{~K}_{3}(\mathrm{O}$ 'Brien and McCully, 1981) and examined in a fluorescent microscope with filters. Number of pollen tubes at upper, middle, base of the style, near the ovule and inside the ovule were counted.

\section{Pollen Germination in Vitro}

During the blooming season, flowers were collected every day from 'Osteen' and 'Kensington'. Flowers were picked up between 9:00-11:00 AM before anther dehiscence and kept at room temperature until anther dehiscence. Then, anthers were removed and placed on 35mm Petri dishes containing $2 \mathrm{~mL}$ of liquid germination medium (Sukhvibul et al. (1999), modified). The next day, pollen germination was recorded. Pollen was considered as germinated when the length of the pollen tube was longer than the grain diameter.

\section{PCR Analysis}

Two paternity assays were performed. One from fruits harvested from 'Osteen' and 'Kent' trees, located in a mango cultivar collection at the IHSM La Mayora, during 2011, and the other from a commercial orchard with two solid blocks: 'Osteen' and 'Keitt', during 2012. DNA was extracted from embryos using the method described by 
Hormaza (2002). PCR amplifications were performed and the PCR products were analysed according to Alcaraz and Hormaza (2011). The results were analysed with the Cervus software (Marshall et al., 1998) to assign paternity.

\section{RESULTS AND DISCUSSION}

\section{Phenology and Flower Anatomy}

The first floral primordia were visible in February-March but panicle axis did not begin to elongate until April. Full flowering was in May, when more than $50 \%$ of the panicle flowers opened. In April the temperature usually was low and a high ratio of male flowers were observed. In the first weeks of June, fruit set started and during this month most fruit drop occurred. Fruit harvesting took place from September to December, depending on the cultivars.

Non-pollinated flowers started dropping 4-5 days after anthesis. In pollinated flowers, pistil weight started to increase 5 days after anthesis. When inflorescences were bagged at the end of flowering, a high fruit drop was observed during the first days following anthesis.

Mango is an andromonoic species, both male and hermaphrodite flowers are similar, but hermaphrodite flowers have a globular ovary with a lateral style and male flowers lack a pistil. In hermaphrodite flowers the stigma is short and horseshoe-shaped (Bachelier and Endress, 2009). Below the stigma, a style connects the stigma to the ovary. The ovary hosts a single ovule, which is unitegmic as in other Anacardiaceae (Bachelier and Endress, 2009). The embryo sac is of Polygonum type, with an egg cell, two synergids, a bi-nucleated central cell and three antipodal cells. One day after pollination the embryo sacs were mature.

\section{Pollen Tube Pathway and Fertilization}

Upon arrival at the stigma pollen grains hydrated, and four hours after pollination pollen grains had already germinated and entered the style. The number of pollen tubes was higher in the upper part of the style, but only one or two pollen tubes arrived to the base of the style, as it occurs in other species (Hormaza and Herrero, 1996). In mango, this pollen tube competition appeared to be mediated by the anatomy of the stylar transmitting tissue that had a funnel shape, with a larger section next to the stigma that was reduced at the stylar base.

Between 8-16h after pollination, pollen tubes reached the ovary and 24h after pollination pollen tubes could be seen inside the ovary. The pollen tube did not penetrate the ovule through the micropyle as it occurs in most species (Herrero, 2000), but instead they traversed the nucellus, between cells, towards the embryo sac to carry out double fertilization. Chalazogamy has been reported in other species of Anacardiaceae as pistachio (Martinez-Palle and Herrero, 1998), but in mango pollen tube penetrated through one side of the nucellus. Three days after pollination the pollen tube had entered the embryo sac, and five days after pollination endosperm nuclei were visible. Twenty days after pollination, the ovary and ovule had increased in size, endosperm nuclei were abundant, but the embryo was latent with few cell divisions. Similar observations had been described in other species of Anacardiaceae (Grundwag, 1976). This occurred, together with abundant secretions between the nucellus and the embryo sac. However, a high proportion of flowers presented ovules with embryo sacs degenerating at different stages of development and secretion in these embryo sacs could no longer be observed. 


\section{Temperature and Pollen Germination}

An increase in pollen germination percentage was observed during the flowering season for both cultivars studied when temperatures were getting warmer. In vitro pollen germination was also studied at different temperatures; $12^{\circ} \mathrm{C}, 20^{\circ} \mathrm{C}$ and $30^{\circ} \mathrm{C}$ with pollen from 'Kensington', 'Osteen' and 'Kent'. At $12^{\circ} \mathrm{C}$ pollen germination was low (30\%, 5\%, $0 \%$ respectively), whereas it was higher at $20^{\circ} \mathrm{C}(70 \%, 39 \%, 45 \%$ respectively) and at $30^{\circ} \mathrm{C}$ (79\%, 47\%, 54\% respectively). Similar results were observed by Sukhvibul et al. (2000) for 'Kensington'. Further work on the temperatures, not only during pollen germination, but also during pollen development may shed light on these differences, as it occurs in other species as cherimoya (Lora et al., 2012), in which temperature in the final stages of pollen development has a reflection on the subsequent pollen performance.

\section{Evaluation of Pollen Pistil-Incompatibility}

The observation of pollen tube growth in controlled cross- and self-crosses showed no differential behaviour of the pollen tubes in the style. Thus, a paternity analysis was conducted. In a first experiment, performed in a mango cultivar collection, the results showed a high percentage of cross-fertilization in 'Osteen' fruits (95\%) and a lower percentage (52\%) in 'Kent'. Due to the high percentage of cross-fertilization observed in 'Osteen', and previous observations showing no production problems in orchards planted with only this cultivar, a second experiment was performed in an orchard with just two cultivars in different opposite plots: 'Osteen' and 'Keitt'. The results showed a high percentage of fruits produced by self-fertilization especially in the trees further away from the pollen donor. Therefore, the results suggest the presence of a cryptic self-incompatibility system in mango that would favour cross-fertilization but, in the absence of pollen from other genotypes, self-fertilization would be possible.

\section{CONCLUSIONS}

Results herein show that low fruit set in mango in Mediterranean climates is due to different causes. The high number of degenerated embryo sacs observed indicates problems in flower quality. But pollen quality was also affected by low temperatures. Finally, although a pollen-pistil incompatibility is considered unlikely because progeny from self-fertilization is viable, a preference for cross-fertilization was found.

\section{ACKNOWLEDGEMENTS}

V. Pérez thanks to Cabildo de La Palma-CSIC for a PhD grant. Support to this work was provided by the Spanish Ministry of Science and Innovation (MICINN)European Regional Development Fund, European Union (AGL2010-15140 and AGL2012-40239 grants).

\section{Literature Cited}

Alcaraz, M. L., and Hormaza, J. I. 2011. Influence of physical distance between cultivars on yield, outcrossing rate and selective fruit drop in avocado (Persea americana, Lauraceae). Ann. App. Biol. 158: 354-361.

Bachelier, J. B., and Endress, P. K. 2009. Comparative floral morphology and anatomy of Anacardiaceae and Burseraceae (Sapindales), with a special focus on gynoecium structure and evolution. Bot. J. Linn. Soc. 159: 499-571. 
Davenport, T. L., and Nuñez-Elisea, R. 1997. The Mango: Botany, production and uses. CAB International, Cambrige, U.K.

Feder, N., and O'Brien, T. 1968. Plant microtechnique: some principles and new methods. Am. J. Bot. 55: 123-142.

Grundwag, M. 1976. Embryology and fruit development in four species of Pistacia L.(Anacardiaceae). Bot. J. Linn. Soc. 73: 355-370.

Hedhly, A., Hormaza, J. I., and Herrero, M. 2009. Global warming and sexual plant reproduction. Trends Plant Sci. 14: 30-36.

Herrero, M. 1992. From pollination to fertilization in fruit trees. Plant Growth Reg. 11: 27-32.

Herrero, M. 2000. Changes in the ovary related to pollen tube guidance. Ann. Bot. 85: 7985.

Hormaza, J. I. 2002. Molecular characterization and similarity relationships among apricot (Prunus armeniaca L.) genotypes using simple sequence repeats. Theor. App. Genet. 104: 321-328.

Hormaza, J. I., and Herrero, M. 1996. Dynamics of pollen tube growth under different competition regimes. Sex. Plant Reprod. 9: 153-160.

Johansen, D. A. 1940. Plant microtechniques. McGraw-Hill, New York.

Lora, J., Herrero, M., and Hormaza, J. I. 2012. Pollen performance, cell number, and physiological state in the early-divergent angiosperm Annona cherimola Mill. (Annonaceae) are related to environmental conditions during the final stages of pollen development. Sex. Plant Reprod. 25: 157-167.

Lora, J., Hormaza, J. I., and Herrero, M. 2010. The progamic phase of an early-divergent angiosperm, Annona cherimola (Annonaceae). Ann. Bot. 105: 221-231.

Marshall, T. C., Slate, J., Kruuk, L. E. B., and Pemberton, J. M. 1998. Statistical confidence for likelihood-based paternity inference in natural populations. Mol. Ecol. 7: 639-655.

Martinez-Palle, E., and Herrero, M. 1998. Pollen tube pathway in chalazogamous Pistacia vera L. Int. J. Plant Sci. 159: 566-574.

Nicholas, J., Gates, P., and Grierson, D. 1986. The use of fluorescence microscopy to monitor root development in micropropagated explants. J. Hort. Sci. 61: 417-421.

O'Brien, T. P., and McCully, M. E. 1981. The study of plant structure: principles and selected methods. Melbourne, Termarcarphi Pty. LTD.

Sukhvibul, N., Hetherington, S., Whiley, A., Smith, M., and Vithanage, V. 1999. Effect of temperature on pollen germination, pollen tube growth and seed development in mango (Mangifera indica L.). Acta Hort.: 609-616.

Sukhvibul, N., Whiley, A. W., Vithanage, V., Smith, M. K., Doogan, V. J., and Hetherington, S. E. 2000. Effect of temperature on pollen germination and pollen tube growth of four cultivars of mango (Mangifera indica L.). Hort. Sci. Biotechnol. 75: 214-222. 